\title{
UNDERSTANDING THE EFFECT OF A SOFT DRINKS INDUSTRY LEVY ON CONSUMER WELL-BEING IN THE UK: FIRST ESTIMATES
}

\author{
Bradley Fage $^{1}$, Aleksandar Vasilev ${ }^{2}$ \\ date of paper receipt: \\ date of sending to review: \\ date of review receipt: \\ 12.12.2020. \\ 27.01.2021. \\ 10.12.2020. \\ doi: 10.2478/eoik-2021-0001 \\ UDK 663.2:658.115]:334.764 \\ Original Article
}

${ }^{1}$ Independent researcher, UK, e-mail: bradleyjamesfage@gmail.com

${ }^{2}$ University of Lincoln, UK, e-mail: avasilev@lincoln.ac.uk

\begin{abstract}
This paper is a first attempt to provide a quantitative evaluation of consumer well-being resulting from the UK Soft Drinks Industry Levy introduced in April 2018. Using a model setup that encompasses both a normal case and a Giffen case for sugary drinks consumption, a computational exercise is performed to quantify the welfare social loss for a variety of household incomes. The model demonstrates that the introduction of a soft drinks levy results in a non-trivial welfare loss, particularly in terms of monetary value and weight effect. We also find that the wealthiest individuals in society are affected positively by this levy, whilst the poorest segment of the population are adversely affected, especially in the presence of a binding nutritional constraint.
\end{abstract}

Keywords:

Soda tax, sugary drinks, Giffen goods, nutritional constraint, welfare social loss. 


\section{INTRODUCTION AND MOTIVATIONS}

In the 2016 Budget, the former Chancellor of the Exchequer, George Osborne announced the introduction of a new tax on sodas, based on the claim that drinks containing added sugar are unhealthy and that their consumption should be discouraged. A similar tax already existed in some countries, like Denmark, Finland and Hungary and in many US states (Berardi et al. 2012). However, the Conservative government decided to extend this tax to non-alcoholic beverages with added sugar or sweetener, and notably sodas, fruit drinks and flavoured waters. Moreover, the tax puts a charge of 24 pence on drinks containing 8 grams of sugar per $100 \mathrm{ml}$ and 18 pence a litre on those with 5-8 grams of sugar per 100ml. This tax was effective from April 6, 2018. Given the short period since the introduction of the soda tax, there are no estimates of the effects of this policy, especially results based on micro-founded models disciplined by data.

The aim of this paper is to address this gap in the literature. We provide some initial estimates based on a relatively standard model, which encompasses the two different tax treatments based on sugar content. The estimated effect is calculated for a households in different income brackets. We then proceed and extend our analysis by allowing for a nutritional constraint in the model setup. This case is often ignored in the literature, so this extension is an important contribution to the literature. Importantly, the presence of the constraint produces quite different results from the benchmark model. While in the standard case consumption of sugary drinks is a normal good, featuring downward-sloping demand, in the case with a binding nutritional constraint, sugary drinks become a Giffen good, and demand is upward-sloping. This change in the sign of the slope has a major repercussions for the effect of the tax policy in the paper, especially for the poorest people in the UK, who might have difficulties with their calorie intake. The welfare effect of the tax policy is then measured using a variety of criteria, such as the monetary value, both in level and as per cent of monthly income, compensatory variations (units of sodas not consumed), and health effects proxied by calories and weight changes.

Before we consider how the economic contribution of the soft drinks industry could be affected by the levy, we first document how household expenditure on soft drinks has developed over the past 25 years in the UK. The observed 'not concentrated' soft drinks consumption tends to grow at a constant rate over time (despite small fluctuations), however as seen from Fig. 1 below, in recent times there has been a tendency away from not low-calorie drinks towards low calorie, as measured by average spending per person per week (in pence).

Figure 1. UK household expenditure on Soft drinks

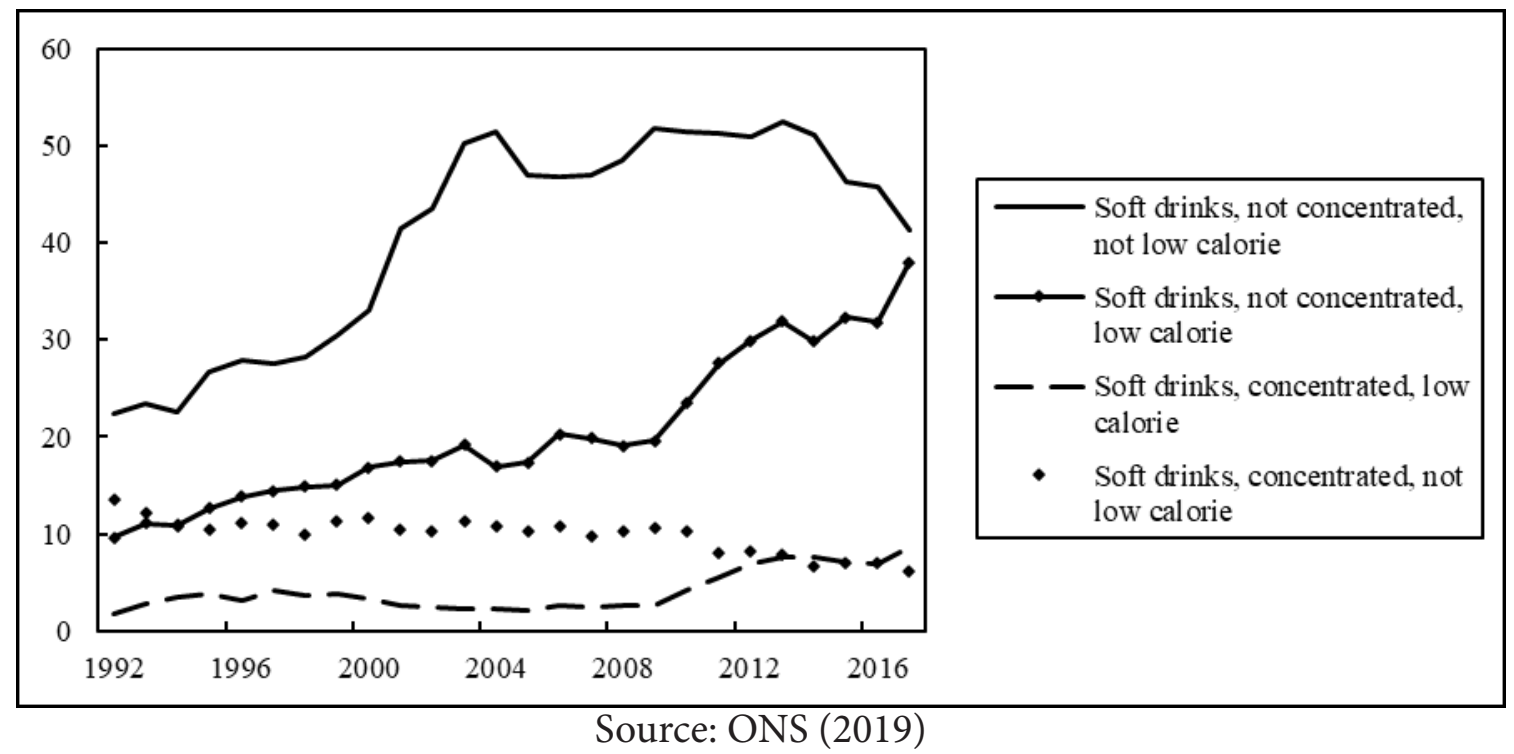


In addition, there has been also a significant upward trend in expenditure on low calorie drinks between 2009-2017; household expenditure on not low-calorie drinks has declined in that period due to substituting between goods (Quirmbach et al. 2018). Another notable deviation is the overlap in concentrated drinks over the 2013-2017 period, and a similar movement away from not low-calorie drinks. In light of that recent trend away from not low-calorie drinks, the increasing prevalence of obesity has led policymakers in the UK trying to reduce sugar consumption in order to minimise the social cost of obesity.

Today, the majority of the population in the OECD area are overweight or obese (Baker, 2018). The obesity epidemic has spread further in the past few years for a select few countries, however as seen from Fig. 2 below, the UK has one of the highest rates amongst them.

Figure 2. Prevalence of overweight (including obesity)

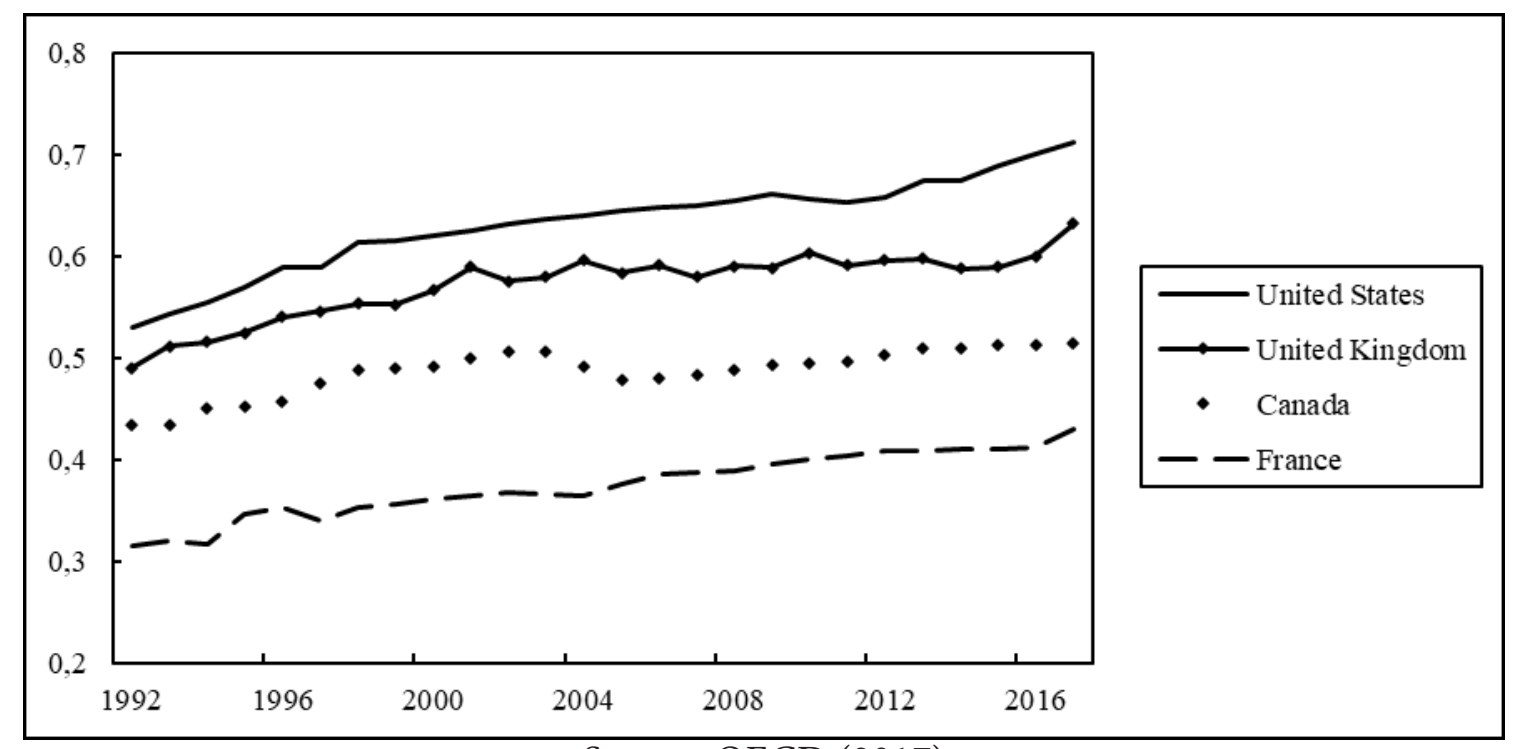

Source: OECD (2017)

The increasing prevalence of obesity has not been a striking one, but there has been a gradual incline over time in the population that are overweight, the fundamental cause of this is an energy imbalance between calories consumed and calories expended. However, globally, there has been an increased intake of energy-dense foods that are high in fat and sugar, as well as an increase in physical inactivity due to the increasingly sedentary nature of many forms of work, changing modes of transportation and increasing urbanization (World Health Organization, 2018). In the last few years, new policy strategies devised to fight obesity have emerged. Many OECD countries rely on fiscal policies to increase the price of potentially unhealthy products (OECD, 2017). This paper studies the effect of the sugar tax in the UK and thus adds value to the existing literature and to the current policy debates. Our research differs in a major way from other similar reforms elsewhere. Depending on the nature of soda consumption, whether it is a normal, or a Giffen good, and the income bracket, the levy could result in substantial weight loss, but for the poorest people in society the result could have the reverse effect and lead to an increase in weight. Therefore, the soft drinks levy could be productive to the wealthiest, but it could be counter-productive to the poorest.

The remaining of the paper is structured as follows: Section 2 provides an overview of the wider literature pertaining to the effect of excise taxes to prices. Section 3 then presents the model setup, and then discusses the main results from the tax policy. Section 4 concludes. 


\section{LITERATURE REVIEW}

Given that the UK government's decision to impose a soft drinks levy is only two years old, the literature is very small. Two recent papers by Cornelsen et al. (2014) and Cornelsen and Carriedo (2015) provide some contemporary analysis of the soft drinks levy in the UK. Cornelsen et al. (2014) acknowledge a substitution effect taking place as the relative price of taxed and untaxed food and beverages change, as the cross-price elasticities are relatively small and close to zero in value. However, both studies were conducted prior to the announcement of the tax and are thus of limited relevance. Even earlier, Leicester and Windmeijer (2004) and Chouinard et al. (2007) argue that such a tax is regressive and unfair, as low-income households in the UK tend to spend a higher proportion of their income on food and beverages, so they may end up paying a greater share of their income in tax. Still, Cornelsen and Carriedo (2015) acknowledge a degree of uncertainty on whether the tax will be fully passed through to consumers, they argue that a tax on unhealthy foods and beverages can only be effective if it is fully passed onto consumers, as this will act as an incentive to reduce consumption. Despite their criticisms, Cornelsen and Carriedo (2015) also provide much stronger evidence that excise taxes do work. They argue the effectiveness of the tax is dependent solely on its design, as a higher tax rate combined with gradual increases and a broader tax base has greater potential to influence health in the long-run.

In the broad literature on indirect taxation, most excise taxes are designed to raise revenue, while others are motivated by non-fiscal considerations and are intended to discourage particular consumption activities (Chiou and Muehlegger, 2010). Taxes on liquor consumption, although they do raise considerable revenue, also are intended to discourage drinking (Hyman, 2014). Golden et al. (2015) argue that excise taxes are generally considered to be one of the most effective ways to reduce the consumption of demerit goods. Given that an important objective of the soft drinks levy is to reduce obesity, as is the case with the sugar tax levy in the UK, the government considers the presence of a negative externality, as sugary drinks are said to damage your health (Allcott et al. 2019). Through increasing the price of sugary drinks, the soft drinks levy is working as a "Pigouvian" tax, aiming to correct the negative externality. The effects of cigarette taxation on smoking should be reviewed, as taxing cigarettes is also a demerit tax, aiming to address health issues. Showalter (1998) argues that these were particularly effective in the US because firms responded by raising prices dramatically. Chiou and Muehlegger (2010) find some evidence that US consumers substitute between quality-tiers in response to tax changes, more specifically, they find that the quantity of low-tier cigarettes rises. In Denmark, obesity concerns were addressed with a tax on foods which exceeded an amount of saturated fat (a "fat tax"). Bergman and Hansen (2010) and Bonnet and Requillart (2010) provide a coherent view on the impact on Danish consumers. However, their work fails to address the broader impact on the industry as it is likely that any additional revenues raised from the excise tax will be offset in terms of VAT or sales taxes. Preece (2013) address this, and identifies that excise taxes designed specifically for raising revenue purposes cannot be recommended or supported as good tax policy. He found that excise taxes re best applied to products for which there are readily available substitutes and the externalities are clear, such as alcohol, tobacco and fuels. However, Griffith et al. (2016) make the point that these principles are very difficult to apply to caloric intake from food and beverages. They also argue that if people have a strong taste for sugar, then they may switch towards chocolate or confectionary rather than low-sugar alternatives.

We take all the findings in the literature seriously and proceed with the analysis of the effects of the sugar tax levy in the UK. In the methodology section, we start from the basic principles, and use the public finance literature as our guide, as commodity taxation, and taxation of demerit goods (excise taxes) is not a new issue. The novelty, and the main contribution of this paper is the quantitative 
nature of our study, and the use of a computational experiment based on a disciplined theoretical model, calibrated to the UK data to provide first estimates on the effect of the sugar tax.

\section{MODEL SETUP}

The setup used is based on a simplified version of Varian (2014). In section 3.1 we will consider the normal case and use this as a benchmark for our analysis. In section 3.2 we will consider the Giffen case and introduce a nutritional constraint to extend our analysis. Both sections will acknowledge a threshold effect and assess our findings for different tax treatments based on sugar content.

\section{BENCHMARK (NORMAL-GOOD) CASE}

The model is static, and there is a representative agent with preferences described by the following utility function:

$$
U\left(x_{1}, x_{2}\right)=\gamma \ln x_{1}+(1-\gamma) \ln x_{2}-y
$$

where $x_{1}$ is a composite good capturing not only the quantity of healthy drinks, but also all other expenditure, e.g. rent; $x_{2}$ is the quantity of sugary drinks. Both commodities are goods, and each features diminishing marginal utility. Parameter $0<\gamma, 1-\gamma<1$ is the weight attached to commodity 1 and 2, respectively. In data, $\gamma=0.98$ (ONS 2019). Finally, the negative term in the utility function, $-y$, aims to capture the adverse effect of obesity on well-being. In other words, the consumption of too many sugary drinks leads to the intake of excess calories, and obesity, following a simple relationship with sugary drinks, $y=\frac{x_{2}}{\bar{x}}-1$. In other words, obesity is expressed in terms of percentage of excessive calories over some reference value $\bar{x}$, which can consist of both sugary drinks or any other food items. Note that when choosing the amount of sugary drinks to be consumed, the agent takes obesity as given, hence there will be a negative externality in the model.

For simplicity, the price of the composite good will be normalized to unity, i.e., $p_{1}=1$, while the price of sugary drinks $p_{2}$, as well as consumer's income $I$, will be taken from data. The budget constraint of the consumer can be expressed as

$$
p_{1} x_{1}+\left(p_{2}+t\right) x_{2}=I
$$

where $p_{1} x_{1}$ is the spending on all other goods (numeraire), and $\left(p_{2}+t\right) x_{2}$ is the amount of money the consumer is spending on sugary drinks, where $t$ is the sugar tax levy. Setting up the Lagrangean function produces

$$
L=\gamma \ln x_{1}+(1-\gamma) \ln x_{2}-y+\lambda\left[I-p_{1} x_{1}-\left(p_{2}+t\right) x_{2}\right]
$$

where $\lambda$ is the Lagrange multiplier attached to the budget constraint. The optimality conditions are as follows:

$$
\begin{array}{r}
\frac{\gamma}{x_{1}}=\lambda p_{1}, \\
\frac{1-\gamma}{x_{2}}=\lambda\left(p_{2}+t\right),
\end{array}
$$




$$
p_{1} x_{1}+\left(p_{2}+t\right) x_{2}=I \text {, }
$$

This produces a system of three non-linear equations in three unknowns $x_{1}, x_{2}, \lambda$, which can be solved for by substitution. The optimal demand for sugary drinks is

$$
x_{2}^{*}=\frac{(1-\gamma) I}{\left(\gamma^{2}-\gamma+1\right)\left(p_{2}+t\right)}
$$

Similarly, for the numeraire:

$$
x_{1}^{*}=\frac{\gamma}{\left(\gamma^{2}-\gamma+1\right)} \frac{I}{p_{1}}
$$

A simple comparative-statics exercise yields that both goods are normal as

$$
\begin{aligned}
& \frac{\partial x_{1}}{\partial I}>0 \\
& \frac{\partial x_{2}}{\partial I}>0
\end{aligned}
$$

Next, with a separable utility function in the arguments, the substitution effect is zero:

$$
\begin{aligned}
& \frac{\partial x_{1}}{\partial p_{2}}=0 \\
& \frac{\partial x_{2}}{\partial p_{1}}=0 .
\end{aligned}
$$

Finally, it is easy to show that both goods will feature downward-sloping demand curves, i.e

$$
\begin{aligned}
& \frac{\partial x_{1}}{\partial p_{1}}<0 \\
& \frac{\partial x_{2}}{\partial p_{2}}<0
\end{aligned}
$$

Now that we have examined the qualitative properties of the optimal demands, we will calibrate the model to data, and use it to perform a computational policy experiment in order to obtain the welfare social loss from the introduction of the soft drinks levy. This is a measure of the inefficiency, or the "excess burden" of the tax, which is due to the fact that the consumer enjoys lower quantities of the good, which are purchased at a higher price (Stiglitz and Rosengard, 2015). This cost is represented by the shaded area in Fig. 3 on the next page (given the small size of the tax, we can ignore the nonlinearity in the demand). 
Figure 3. Welfare social loss.

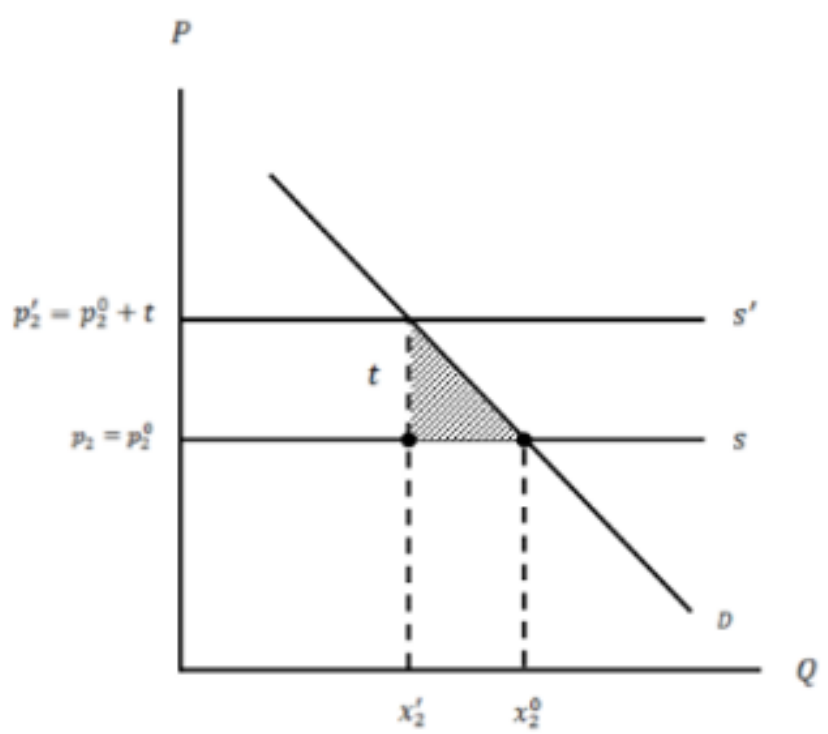

Source: Created by author(s)

Note that we have assumed that the supply curve is horizontal (perfectly elastic). In other words, merchants will pass all the tax burden onto consumers. This assumption is mainly used for simplicity, as it allows us to abstract from the firm side. In addition, with horizontal supply curve, the welfare cost is entirely a loss in consumer surplus, and thus the estimates provided later in the paper are to be interpreted as an upper-bound of the possible effect.

Next, we outline the computational procedure for the welfare social: if the initial price for a sugary drink is denoted by $p_{7}^{0}$, after the introduction of the sugar tax the price increases from $p_{7}^{0}$ to $p_{7}^{0}+t$ . We assume that the individual's consumption is $x_{2}^{0}$ before the tax and this decreases to $x_{2}^{\prime}$ after the tax. The welfare social loss is measured by the shaded area under the demand schedule and above $p_{\text {? }}^{0}$, between the output with and without the tax. The triangle is referred to as the Harberger triangle (Stiglitz and Rosengard, 2015), and the symbolic solution for this welfare social loss can be expressed as

$$
W S L=\frac{t\left(x_{2}^{0}-x_{2}^{\prime}\right)}{2}
$$

where $=p_{2}^{\prime}-p_{2}^{0}$. A more detailed representation of the cost is

$$
W S L=\frac{t}{2} \frac{(1-\gamma) I}{\left(\gamma^{2}-\gamma+1\right) p_{2}\left(p_{2}+t\right)}
$$

In other words, the welfare social loss is a linear function of the tax rate (which is dependent on the sugar content), and income, while gamma and the price of sugary drinks enter in a non-linear way.

Now that we have obtained a symbolic solution, we quantify the tax effect. For that purpose, we will vary the level of income. The minimum monthly income of $£ 1185.10$ was constructed using the $£ 7.83$ hourly rate (ONS, 2018). Alternative incomes for various deciles of the population were then constructed as multiples of the minimum income, capturing the effects for people in different deciles of the income distribution. We compute the size of the welfare social loss using a variety of criteria. The first and second measures are in terms of monetary value and share of monthly income, and thus aim to capture the financial effects. The third, fourth and fifth measures focus 
directly on health effects. This will be illustrated in terms of the percentage change in sugary drinks consumption, decrease in the calories consumed, and loss in weight (kilograms), which addresses the obesity dimension outlined in Section 1. In Table 1 on the next page, we summarise the welfare effect when the tax is 24 pence. We use that 1 litre of soda equals approximately $400 \mathrm{kcal}$, and that burning $4068 \mathrm{kcal}$ decreases one's weight by $1 \mathrm{~kg}$.

Table 1. Normal Good Welfare Effect with $t=0.24$

\begin{tabular}{llllll}
\hline Income & $\mathfrak{E}$ & $\%$ & $\Delta \mathrm{x} 2$ & $\Delta \mathrm{kcal}$ & $\Delta \mathrm{kg}$ \\
\hline $\mathrm{I}\{\min \}$ & -1.79 & -0.15 & -1.54 & -616 & -0.102 \\
$\mathrm{I}\{\min \} 1.1$ & -1.96 & -0.15 & -1.69 & -677.6 & -0.110 \\
$\mathrm{I}\{\min \} 1.2$ & -2.14 & -0.15 & -1.85 & -739.2 & -0.122 \\
$\mathrm{I}\{\min \} 1.5$ & -2.68 & -0.15 & -2.31 & -924 & -0.150 \\
$\mathrm{I}\{\min \} 2$ & -3.57 & -0.15 & -3.08 & $-1,232$ & -0.204 \\
$\mathrm{I}\{\min \} 5$ & -8.93 & -0.15 & -7.70 & $-3,080$ & -0.500 \\
$\mathrm{I}\{\min \} 10$ & -17.86 & -0.15 & -15.40 & $-6,160$ & -1.020 \\
\hline
\end{tabular}

Source: Calculated by author(s)

As seen from table 1 above, the share of monthly income is constant between all income groups. This is expected given that income shows up in the numerator of Eq. (16) to scale up the welfare social loss, so when we divide this income by the scaled-up version, the effect cancels out. The fiscal burden of the tax is very small, but so is the revenue effect. Next, the WSL from the sugar tax is higher for the higher income groups, and the effect on obesity is stronger. This is consistent with anecdotal evidence that richer people have better eating habits. We can say that a welfare loss of 0.15 per cent of income is relatively small and will not have a huge impact the consumer. The results also show that there are some notable variations. When we measure the effect in terms of units of sugary drinks not consumed, it can be seen that the poorest individuals are likely to save, on average, 1.54 litres of sugary drinks per month as a result of the levy. When we measure the effect in terms of kilograms, the loss is approximately $0.1 \mathrm{~kg}$ per month, or $1.2 \mathrm{~kg}$ per year, and does not vary much with poorer income shares.

In Table 2 we repeat this exercise for when the good is normal and the tax is 18 pence. As seen from the results, higher income groups again generate a larger welfare social loss (but they also benefit more in terms of weight loss from the cut in consumption) when the levy is adopted.

Table 2. Normal Good Welfare Effect with $t=0.18$

\begin{tabular}{|c|c|c|c|c|c|}
\hline Income & $\mathfrak{E}$ & $\%$ & $\Delta \mathrm{x} 2$ & $\Delta \mathrm{kcal}$ & $\Delta \mathrm{kg}$ \\
\hline $\mathrm{I}\{\min \}$ & -1.40 & -0.12 & -1.21 & -484 & -0.080 \\
\hline $\mathrm{I}\{\min \} 1.1$ & -1.54 & -0.13 & -1.33 & -532 & -0.088 \\
\hline $\mathrm{I}\{\min \} 1.2$ & -1.68 & -0.14 & -1.45 & -581 & -0.096 \\
\hline $\mathrm{I}\{\min \} 1.5$ & -2.10 & -0.18 & -1.80 & -726 & -0.120 \\
\hline $\mathrm{I}\{\min \} 2$ & -2.80 & -0.24 & -2.42 & -968 & -0.160 \\
\hline $\mathrm{I}\{\min \} 5$ & -7.0 & -0.60 & -6.05 & $-2,420$ & -0.400 \\
\hline $\mathrm{I}\{\min \} 10$ & -14.00 & -1.2 & -12.10 & $-4,840$ & -0.800 \\
\hline
\end{tabular}

Similar to when the tax is 24 pence, the share of income is constant between all income groups. This time we can say that the share is even smaller at $0.12 \%$ of income and will not have a huge impact on the consumer. It can be seen that the poorest individuals are likely to save, on average, 1.2 litres of sugary drinks per month, as a result of the levy. The effect in terms of kilograms is small, as the loss is approximately 0.08 kilograms per month and is similar across lower income groups. 
Now that we have exhausted the normal case, this section will proceed by exploring the Giffen case and introducing a nutritional constraint. This is a case that is often dismissed by many studies; therefore, it would be interesting to understand whether the presence of this constraint would produce different results from the benchmark case.

\section{THE GIFFEN CASE}

We now extend the benchmark model with a nutritional constraint. This constraint aims to capture the fact that it might be likely that poorer individuals require sugary drinks as a way to reach a certain calorific benchmark:

$$
c_{1} x_{1}+c_{2} x_{2} \geq C
$$

where $c_{1}$ is the number of calories per 1 unit of the numeraire and $c_{2}$ is the number of calories per 1 unit from sugary drinks, and where $x_{1}$ is the numeraire, and $x_{2}$ is the quantity of sugary drinks. In total this should exceed $\mathrm{C}$ which this is the necessary number of calories to be functional, for example 2,000. Like the benchmark case, we set up the Lagrangian function, which now also incorporates the nutrition constraint above, or:

$$
L=\gamma \ln x_{1}+(1-\gamma) \ln x_{2}-y+\lambda\left[I-p_{1} x_{1}-\left(p_{2}+t\right) x_{2}\right]+\mu\left[C-c_{1} x_{1}-c_{2} x_{2}\right],
$$

where $\mu$ is the multiplier attached to the nutritional constraint. Note that when the nutritional constraint is not binding, we are back in the benchmark case. This case is relevant for the middleand high-income groups.

Therefore, we will focus on the instances when the nutritional constraint is binding. This might be true for low income groups, and as will show, with nutritional constraint, the soft drinks levy might affect them adversely. The first-order optimality conditions are:

$$
\begin{aligned}
& x_{1}: \frac{\gamma}{x_{1}}=\lambda p_{1}+\mu c_{1} \\
& x_{2}: \frac{1}{x_{2}}=\lambda\left(p_{2}+t\right)+\mu c_{2}
\end{aligned}
$$

Plus the budget and the nutritional constraint. In this case, finding an explicit solution for $x_{1}$ and $x_{2}$ is a bit complex as we have to solve a non-linear system of equations, as now we have a system of four non-linear equations in four unknowns which we have to solve numerically in the general case. However, given that the two constraints are binding, it is easy to establish that the optimal choices for $x_{1}$ and $x_{2}$ should lie at the intersection of the budget and nutritional constraints, as seen from Fig. 4 below. 
Figure 4. Intersection of constraints.

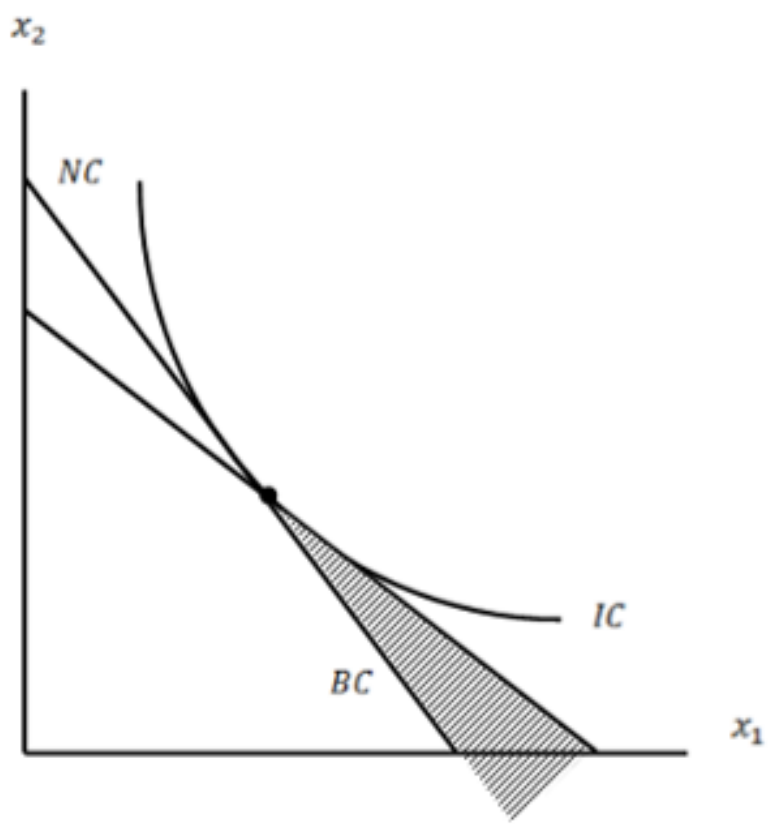

Source: Created by author(s)

The argument goes as follows: the budget constraint represents the set of allocations that is feasible, which is the space below the budget line; the nutrition constraint, which is a minimum condition, says that the allocations have to be to the right of its respective line. The intersection of the budget set and the nutritional constraint is represented by the shaded area above. Given that the utility function is logarithmic, the indifference curve at the optimum will be tangent to the shaded area at the intersection of the budget line and the nutritional constraint. This provides a useful shortcut for our analysis, as this means that we only have to solve a linear system of two equations (the two binding constraints). In matrix form, the system is

$$
\left[\begin{array}{cc}
p_{1} & p_{2}+t \\
c_{1} & c_{2}
\end{array}\right]\left[\begin{array}{l}
x_{1} \\
x_{2}
\end{array}\right]=\left[\begin{array}{l}
I \\
C
\end{array}\right]
$$

To solve for the optimal demands $x_{1}^{*}$ and $x_{2}^{*}$ we make use of the Cramer's rule. This produces

$$
x_{1}^{*}=\frac{\left|\begin{array}{cc}
I & p_{2}+t \\
C & c_{2}
\end{array}\right|}{\left|\begin{array}{cc}
p_{1} & p_{2}+t \\
c_{1} & c_{2}
\end{array}\right|}
$$

or

$$
x_{1}^{*}=\frac{I c_{2}-C\left(p_{2}+t\right)}{p_{1} c_{2}-c_{1}\left(p_{2}+t\right)}>0
$$

Similarly, for $x_{?}^{*}$

$$
x_{2}^{*}=\frac{\left|\begin{array}{ll}
p_{1} & I \\
c_{1} & C
\end{array}\right|}{\left|\begin{array}{cc}
p_{1} & p_{2}+t \\
c_{1} & c_{2}
\end{array}\right|}
$$

or

$$
x_{2}^{*}=\frac{p_{1} C-I c_{1}}{p_{1} c_{2}-c_{1}\left(p_{2}+t\right)}>0
$$


Now that we have the optimal demand functions for healthy drinks and sugary drinks in the giffen case, we can proceed with comparative statics. Similar to the benchmark case, it is useful to understand how the behaviour of optimal sugary drinks $x_{2}^{*}$ is affected when some of the parameters change. Ignoring the tax for now (which will later show up as a change in $p_{2}$ ), the UK data suggests that both the numerator and denominator are positive, or

$$
\begin{aligned}
& p_{1} C-I c_{1}>0 \\
& p_{1} c_{2}-c_{1} p_{2}>0
\end{aligned}
$$

or

$$
\begin{aligned}
& \frac{p_{1}}{I}>\frac{c_{1}}{C} \\
& \frac{p_{1}}{p_{2}}>\frac{c_{1}}{c_{2}}
\end{aligned}
$$

In other words, the first condition states that the price of the numeraire relative to income exceeds the relative calorie content, while the second is a "quality-to-price" condition, which can be expressed as the price ratio exceeding the relative calorie content.

Now we can totally differentiate the original two-equation system to obtain

$$
\begin{aligned}
& x_{1} d p_{1}+p_{1} d x_{1}+x_{2} d p_{2}+p_{2} d x_{2}=d I \\
& x_{1} d c_{1}+c_{1} d x_{1}+x_{2} d c_{2}+c_{2} d x_{2}=d C
\end{aligned}
$$

Rearrange terms and express back into matrix form

$$
\left[\begin{array}{ll}
p_{1} & p_{2} \\
c_{1} & c_{2}
\end{array}\right]\left[\begin{array}{l}
d x_{1} \\
d x_{2}
\end{array}\right]=\left[\begin{array}{l}
d I-x_{1} d p_{1}-x_{2} d p_{2} \\
d C-x_{1} d c_{1}-x_{2} d c_{2}
\end{array}\right]
$$

To perform comparative statics, we make use of the Cramer's rule once more (Chiang, 1984). We focus on sugary drinks:

$$
\frac{d x_{2}}{d I}=\frac{\left[\begin{array}{cc}
p_{1} & 1 \\
c_{1} & 0
\end{array}\right]}{\left[\begin{array}{ll}
p_{1} & p_{2} \\
c_{1} & c_{2}
\end{array}\right]}=-\frac{c_{1}}{p_{1} c_{2}-c_{1} p_{2}}<0
$$

As already know that $c_{1}$ is positive, and we established that the denominator is also positive using data on prices and calorie content. Therefore, the second good (sugary drinks consumption) is inferior. In a two-goods economy, when one is inferior, the other good (the numeraire) has to be normal.

Still, inferiority is a necessary, but not a sufficient, condition for the good to be Giffen. However, given that the substitution effect is zero in our model, it is straightforward to establish that an inferior good has to be necessarily also Giffen. In the general case, for a good to be Giffen, the income effect also has to dominate the substitution effect. Indeed, this is true in our model, as

$$
\frac{d x_{2}}{d p_{2}}=\frac{c_{1} x_{1}}{p_{1} c_{2}-c_{1} p_{2}}>0
$$


In other words, in the Giffen case, illustrated in Fig. 5 on the next page, the demand is now upward sloping, as demand for sugary drinks is no longer normal (ordinary). When the good is Giffen, the higher the price is, which is the case with a sugar tax, then more sugary drinks will be consumed by the poorest households, who have trouble getting the necessary amount of calories.

Figure 5. Welfare social loss.

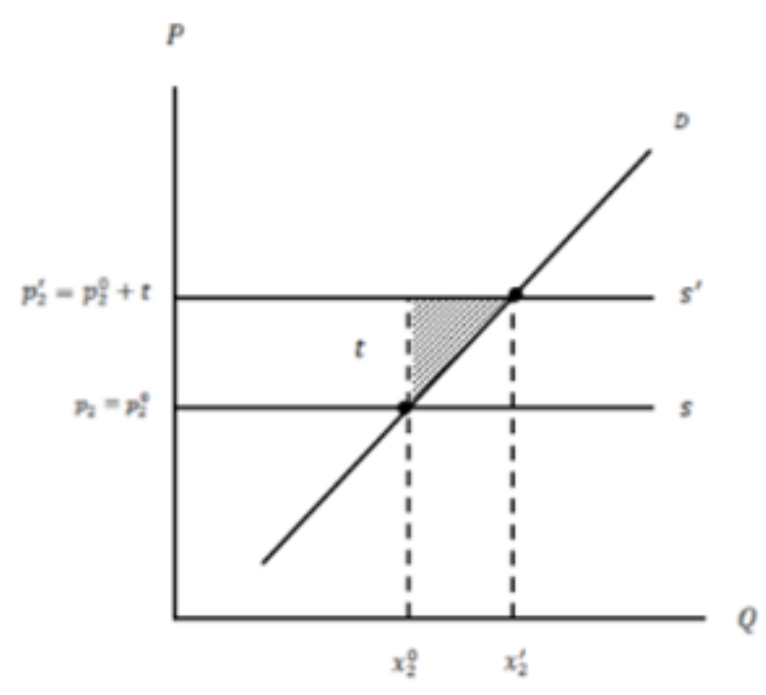

Source: Created by author(s)

Similarly to the normal case, we can express (again ignoring the nonlinearity of the demand curve) the welfare social loss when sugary drinks are Giffen is

$$
W S L=\frac{t\left(x_{2}^{\prime}-x_{2}^{0}\right)}{2}
$$

or

$$
W S L=\frac{t^{2}}{2} \frac{\left[-p_{1} C+I c_{1}\right] c_{1}}{\left[p_{1} c_{2}-c_{1}\left(p_{2}+t\right)\right]\left[p_{1} c_{2}-c_{1} p_{2}\right]}
$$

In order to obtain the quantitative effect, we set $\mathrm{C}=2000 \mathrm{kcal}, c_{1}=100 \mathrm{kcal}, c_{2}=400 \mathrm{kcal}$, $p_{1}=1, p_{2}=1.16$. Table 3 summarises the welfare social loss when the good is Giffen and the tax is 24 pence. We assume that for households earning twice the minimum income and above, the nutritional constraint is not binding, and thus the consumption of sugary drinks is a normal good.

Table 3. Giffen Good, Welfare Effect with $t=0.24$

\begin{tabular}{llllll}
\hline Income & $\mathfrak{E}$ & $\%$ & $\Delta \mathrm{x} 2$ & $\mathrm{kcal}$ & $\Delta \mathrm{kg}$ \\
\hline $\mathrm{I}\{\min \}$ & -4.46 & -0.38 & 3.85 & 1,540 & 0.379 \\
$\mathrm{I}\{\min \} 1.1$ & -4.92 & -0.38 & 4.24 & 1,697 & 0.417 \\
$\mathrm{I}\{\min \} 1.2$ & -5.38 & -0.38 & 4.63 & 1,854 & 0.456 \\
$\mathrm{I}\{\min \} 1.5$ & -6.74 & -0.39 & 5.81 & 2,324 & 0.571 \\
$\mathrm{I}\{\min \} 2$ & -9.01 & -0.39 & 7.77 & 3,107 & 0.764 \\
\hline
\end{tabular}

Source: Calculated by author(s)

Again, as seen from the table, higher income groups generate a larger welfare social loss when the sugar tax is adopted. When the good is Giffen, the share of income lost is no longer constant, 
instead it increases as income increases. The effect is not quantitatively significant, though. Next, focusing on the health effects, in contrast to the normal case, here the sign of the effect is completely opposite. This is because instead of helping the poorest people in society, the levy is now hurting them because this additional tax means they end up consuming more sugary drinks and become more obese (the gain in kilograms is positive). Depending on the level of income, the weight gain ranges between $0.38-0.57 \mathrm{~kg}$ per month, which becomes $4.56-6.84 \mathrm{~kg}$ weight gained per year, a nontrivial effect. Our estimates suggest that the presence of a nutritional constraint is very important, especially for the poorest individuals, and should be considered by policy makers if they want to address the obesity dimension, as the tax actually may exacerbate the problem, especially among the poorest households.

In Table 4 we repeat this exercise for when the good is Giffen when the tax is 18 pence. As seen from the table, higher income groups again generate a larger welfare social loss (and higher weight gain) when the sugar tax is adopted. The quantitative effect is much smaller, though.

Table 4. Giffen Good, Welfare Effect with $t=0.18$

\begin{tabular}{llllll}
\hline Income & $\mathfrak{E}$ & $\%$ & $\Delta \mathrm{x} 2$ & $\Delta \mathrm{kcal}$ & $\Delta \mathrm{kg}$ \\
\hline I\{min\} & -2.46 & -0.21 & 2.12 & 846 & 0.208 \\
$\mathrm{I}\{\min \} 1.1$ & -2.71 & -0.21 & 2.33 & 933 & 0.229 \\
$\mathrm{I}\{\min \} 1.2$ & -2.96 & -0.21 & 2.55 & 1091 & 0.251 \\
$\mathrm{I}\{\min \} 1.5$ & -3.71 & -0.21 & 3.19 & 1278 & 0.314 \\
$\mathrm{I}\{\min \} 2$ & -4.95 & -0.21 & 4.27 & 1708 & 0.420 \\
\hline
\end{tabular}

Source: Calculated by author(s)

Our findings confirm that the effect of the sugar tax is not uniform, and depends on which income bracket the consumer is in. If you are poor, then soda tax affects you adversely due to importance of the nutritional constraint. However, if you are rich, then this policy affects you positively because the nutritional constrain is not binding for the latter. Our findings are in line with the work by Leicester and Windmeijer (2004) and Chouinard et al. (2007) who also posit that the levy will have the reverse effect and affect the poorest in society the most. The same authors suggest that lowincome households will spend a higher proportion of their income in tax, resulting from the levy. In contrast, our results show that the welfare loss as a share of income is essentially constant across all income groups, and is thus consistent with the likes of Cornelsen and Carriedo (2015). These authors provide evidence that the effectiveness of the tax is dependent on its design, where a higher tax rate has greater potential to influence health than a lower tax rate. The findings in this paper are consistent with that view, as the 24-pence tax has a greater influence on weight compared to the 18-pence tax in the model presented here. 


\section{CONCLUSIONS}

This paper was the first attempt to provide a quantitative evaluation of consumer well-being from the introduction of soft drinks levy in the UK in 2018. Using a model setup that encompasses both a normal case and a Giffen case for sugary drinks consumption, a computational exercise is performed to quantify the welfare social loss for a variety of household incomes. The model demonstrates that the introduction of a soft drinks levy results in a non-trivial welfare loss, particularly in terms of monetary value and weight effect. We also find that the wealthiest individuals in society are affected positively by this levy, whilst the poorest segment of the population are adversely affected, especially in the presence of a binding nutritional constraint.

This study is constrained by several limitations: the first is that due to the lack of data, it used a static, and partial equilibrium approach. In other words, this paper produced estimates that are snapshots of the current economy. The second limitation was the assumption of a horizontal supply curve. As an extension, the model may incorporate explicitly producers, and their profit maximisation problem. After all, firms may decide to switch to producing drinks with sugar content below the taxable threshold. This substitution effect would produce a positively-sloped supply curve, which would affect the welfare loss. Due to data limitations, this venue is also left outside the scope of the paper. Extending the setup to a dynamic, general equilibrium setting, and capturing changes in consumer behaviour over time is also left for future research. 


\section{REFERENCES}

Allcott, H., Lockwood, B. and Taubinsky, D. (2019) "Should We Tax Sugar-Sweetened Beverages? An Overview of Theory and Evidence." New York University, Mimeo.

Baker, C. (2018) Obesity Statistics. London: House of Commons Library. Berardi, N., Sevestre, P., Tepaut, M. and Vigneron, A. (2012) “The Impact of a 'Soda Tax' on

Prices. Evidence from French Micro Data.” Working Paper 415/2012, Bank of France, Paris, France.

Bergman, M. and Hansen, N. (2010) "Are Excise Taxes on Beverages Fully Passed Through to Prices? The Danish Evidence.” University of Copenhagen, Mimeo.

Besley, T. and Rosen, H. (1999) Sales Taxes and Prices: An Empirical Analysis. National Tax Journal, 52(2): 157-178.

Bonnet, C. and Requillart, V. (2010) "Is the EU Sugar Policy Reform Likely to Increase Obesity?" European Association of Agricultural Economists, 115th Joint EAAE/AAEA Seminar, September 15-17, 2010, Freising-Weihenstephan, Germany 116414.

Brown, T., Platt, S. and Amos, A. (2013) "Equity impact of interventions and policies to reduce smoking in youth: systematic review." Tobacco Control, 23(2): e98-e105.

Chiou, L. and Muehlegger, E. (2010) "Consumer Response to Cigarette Excise Tax Changes." HKS Faculty Research Working Paper Series, RWP10-020, Harvard University.

Christiansen, V. and Smith, S. (2009) "Externality-Correcting Taxes and Regulation." Institute for Fiscal Studies Working Paper 0916, London, UK.

Cornelsen, L. and Carriedo, A. (2015) "Health-related taxes on food and beverages." London: Food Research Collaboration.

Dolan, E. (2015) The Economics of a Soda Tax. Working Paper. Available from https://www.slideshare.net/dolaneconslide/the-economics-of-a-soda-tax-43658954 [accessed 29 March 2019].

Fullerton, D. and Metcalf, G. (2002) Tax Incidence. Handbook of Public Economics, 4: 17871872.

Golden, S., Holt Smith, M., Feighery, E., Roeseler, A., Rogers, T. and Ribisl, K. (2015) "Beyond excise taxes: a systematic review of literature on non-tax policy approaches to raising tobacco product prices." Tobacco Control, 25(4): 377-85.

GOV.UK (2018) Check if your drink is liable for the Soft Drinks Industry Levy. London: GOV.UK.

Griffith, R., Luhrmann, M., O'Connell, M. and Smith, K (2016) Using taxation to reduce sugar consumption. London: Institute for Fiscal Studies.

Hyman, D. (2014) Public Finance: A Contemporary Application of Theory to Policy, $11^{\text {th }}$ edition. Stamford: Cengage Learning.

Morrissey, O. (2016) “Tax Revenue Performance and Vulnerability in Developing Countries." The Journal of Development Studies, 52(12): 1689-1703.

OECD (2017) OECD Obesity Update 2017. Paris: OECD.

ONS (2017) Family Spending in the UK: Financial Year Ending 2017. Newport: Office for National Statistics.

ONS (2018) Jobs paid below minimum wage by category. Newport: Office for National Statistics.

ONS (2019) Average actual weekly hours of work for full time workers (seasonally adjusted). Newport: Office for National Statistics.

ONS (2019) Consumer price inflation basket of goods and services: 2019. Newport: Office for National Statistics. 
Preece. R. (2013) The Effective Contribution of Excise Taxation on Non-Alcoholic Beverages to Government Revenues and Social Objectives: A Review of the Literature. World Customs Journal, 7(1): 21-38.

Quirmbach, D., Cornelsen, L., Jebb, S., Marteau, T. and Smith, R. (2018) "Effect of increasing the price of sugar-sweetened beverages on alcoholic beverage purchases: an economic analysis of sales data." Journal of Epidemiology \& Community Health, 72(4): 324-330.

Showalter, M. (1998) “The Effect of Cigarette Taxes on Cigarette Consumption." American Journal of Public Health, 88(7): 1118-1119.

Stiglitz, J. and Rosengard, J. (2015) Economics of the Public Sector, $4^{\text {th }}$ edition. W. W. Norton \& Company, New York.

Varian, H. (2014) Intermediate Microeconomics, th $^{\text {th }}$ edition. W. W. Norton \& Company, New York.

Vasilev, A. (2015) "Welfare Effect of Flat Income Tax Reform: The Case of Bulgaria," Eastern European Economics 53(3): 205-20

World Health Organization (2018) Obesity and overweight. Geneva: World Health Organization. 
APPENDIX : DETAILS OF THE SOFT DRINKS INDSUTRY LEVY

In accordance with GOV.UK (2018)

\section{Drinks that are liable for the levy}

A drink is liable for the Soft Drinks Industry Levy if it meets all of the following conditions:

it has had sugar added during production, or anything (other than fruit juice, vegetable juice and milk) that contains sugar, such as honey

it contains at least 5 grams (g) of sugar per 100 millilitres $(\mathrm{ml})$ in its ready to drink or diluted form

- $\quad$ its either ready to drink, or to be drunk it must be diluted with water, mixed with crushed ice or processed to make crushed ice, mixed with carbon dioxide, or a combination of these

- $\quad$ its bottled, canned or otherwise packaged so it's ready to drink or be diluted

- $\quad$ it has a content of $1.2 \%$ alcohol by volume (ABV) or less

\section{Drinks that are not liable for the levy}

The levy does not apply to drinks that are:

- $\quad$ at least $75 \%$ milk

- $\quad$ a milk replacement, like soya or almond milk

- $\quad$ an alcohol replacement, like de-alcoholised beer or wine

- $\quad$ made with fruit juice or vegetable juice and do not have any other added sugar

- $\quad$ liquid drink flavouring that's added to food or drinks like coffee or cocktails

- $\quad$ sold as a powder

- $\quad$ prepared by mixing liquids and severed in an open container, like cocktails

- $\quad$ infant formula, follow on formula or baby foods

- $\quad$ formulated food intended as a total diet replacement, or dietary food used for special medical purposes 


\section{ADDENDUM}

This addendum section aims to provide a brief summary describing the data sources used throughout this paper. There are two main sources of data this paper refers to in Section 1. Introduction and Motivations, which in turn are used to generate FIG. 1 and FIG. 2.

First, data used in FIG. 1 UK household expenditure on Soft drinks, has been taken from the Office for National Statistics (ONS) in 2019. This is the executive office of the UK Statistics Authority, a non-ministerial department which reports directly to the UK Parliament. It is also the largest producer of official statistics and the recognised national statistical institute of the UK. The ONS updates and re-publishes data regularly (usually per annum) providing viewers with a contemporary view of the subject matter they are researching, in this case household expenditure on Soft drinks. The ONS provides data free at the point of use and is available within the public domain.

Second, data used in FIG. 2 Prevalence of overweight (including obesity) has been taken from the Organisation for Economic Co-operation and Development (OECD) in 2017. This is an intergovernmental economic organisation with 37 member countries, at the time this paper was written, it was founded to stimulate economic progress and world trade. It's role specifically within the UK is to provide data, policy advice and research on the UK economy. Both sources of data were taken within two years at the time this paper was written, they are both therefore deemed to be accurate sources of data, ultimately providing readers with the most contemporary view of this subject. 